\title{
Modeling Antecedents in Trust-Commitment Vendor Relationships
}

\author{
Janice M. Payan, Joe Hair, Göran Svensson, Svante Andersson, \\ and Gabriel Awuah
}

\begin{abstract}
The primary purpose of this study is to examine the importance of selected antecedents (i.e., cooperation, coordination, and relationship investments) in a commitment-trust vendor relationship model. Collaboration in organizations often is not effective in relationships between purchasers and vendors because cooperation, coordination, and relationship investment are lacking. Research on these constructs is very limited in interorganizational research, so this study is unique, therefore, in examining antecedents in a trust-commitment relationship model. Following examination of both first- and second-order modeling approaches, findings show the influence of these antecedents on trust and commitment, and ultimately vendor relationship satisfaction. All three antecedents are positively related to the higher order management factors construct, and in turn to both trust and commitment, with the stronger relationship being to commitment. Commitment and trust are both positively related to relationship satisfaction. The direct relationship from trust to satisfaction is the strongest, but there is evidence of partial mediation through the indirect relationship from trust to commitment and then to satisfaction.
\end{abstract}

\footnotetext{
J.M. Payan ( $\square)$

University of Northern Colorado, Greeley, CO, USA

e-mail: janice.payan@unco.edu

J. Hair

Kennesaw State University, Kennesaw, GA, USA

e-mail: joehair3@kennesaw.edu

G. Svensson

Oslo School of Management, Oslo, Norway

e-mail: gosv@hh.se
}

S. Andersson • G. Awuah

Halmstad University, Halmstad, Sweden

e-mail: svan@hh.se; Gabriel.Awuah@hh.se

L. Petruzzellis, R.S. Winer (eds.), Rediscovering the Essentiality of Marketing, Developments in Marketing Science: Proceedings of the Academy of Marketing Science, DOI 10.1007/978-3-319-29877-1_65 